\title{
MEMORY AND COGNITIVE ABILITIES IN UNIVERSITY PROFESSORS: Evidence for Successful Aging
}

\author{
Arthur P. Shimamura, ${ }^{1}$ Jane M. Berry, ${ }^{2}$ Jennifer A. Mangels, ${ }^{1}$ \\ Cheryl L. Rusting, ${ }^{3}$ and Paul J. Jurica ${ }^{1}$ \\ ${ }^{1}$ University of California, Berkeley, ${ }^{2}$ Untversity of Richmond, and ${ }^{3}$ University of Michigan, Ann Arbor
}

Abstract-Professors from the Untversity of California at Berkeley were administered a 90 -min test battery of cognitive performance that included measures of reaction time, pairedassociate learning, working memory, and prose recall Age effects among the professors were observed on tests of reaction time, paired-associate memory, and some aspects of working memory Age effects were not observed on measures of proactive interference and prose recall, though age-related declines are generally observed in standard groups of elderly individuals The findings suggest that age-related decrements in certain cognitive functions may be mitigated in intelligent, cognitively active individuals

Genetics, experience, health, personality, and culture all contribute to changes in mental abilities across the adult life span Scientific investigations of age-related changes have been complicated by these diverse factors Indeed, many studies of cognitive aging reveal enormous variability among older adults (Albert, Duffy, \& Naeser, 1987, Heron \& Chown, 1967, Perlmutter, 1978, Shimamura, 1990, Zelınskı, Glewskı, \& Schase, 1993) That is, some older adults exhibit only mild or moderate changes in cognitive function, whereas others exhibit significant and sometimes debilitating deficits This vanability is due in part to problems in controlling for the many factors that affect performance in a group of older adults For example, cognitive performance can be affected considerably by subject factors, such as educational experience, health status, and lifestyle

In this investigation, we focused on memory and cognitive abilities in university professors There are several reasons for analyzing aging effects in this special population First, the subjects are closely matched on intellectual capacity and education Level of intellectual function can greatly influence performance on cognitive measures, and groups with varying levels of intelligence can increase within-group vanability Second, the subjects share simular cultural expenences, such as work environment and socioeconomic status Controlling extraneous factors, such as intelligence and cultural expenence, may make it possible to relate age-related changes to problems in specific components of cognitive function, and perhaps even to certain biological factors Finally, and most important, an analysis of individuals who are mentally active throughout the life span may provide clues to successful aging (Baites \& Baltes, 1990 ,

Address correspondence to Arthur P Shimamura, Department of Psychology, Unuversty of Calıforna, Berkeley, Berkeley, CA 94720. c-mal aps@ganet berkeley edu
Schaie, 1990, 1994) That is, professors may develop efficient use of cognitive abilities or strategies that may prevent or mitigate aging effects

University professors between the ages of 30 and 71 years were administered a battery of memory and cognitive tests The particular tests were chosen because they were known to be sensituve markers of age-related changes $(e \mathrm{~g}$, choice reaction time, free recall) or known to be associated with circumscribed neurological dysfunction (e $\mathrm{g}$, medial temporal or frontal lobe impairment) Several hypotheses were entertained with regand to the identification of successful aging For instance, professors may generally perform well, but age-related changes may still be present That is, performance by professors may be similar to that observed in standard studies of aging but perhaps differ only in the magnitude of age-related changes Alternauvely, there may be qualitative differences between patterns of performance exhibited by professors and by standard groups of elderly people Indeed, it may be that some cognitive abulitues change differently or do not at all diminish during the working years in professors

\section{METHOD AND RESULTS}

\section{Subjects}

We tested 72 professors who were employed at the University of Caiffornia, Berkeley Subjects were divided into three age groups 22 young professors ( 16 men, 6 women), who averaged 384 years of age (range $=30-44$ years) and 22 years of education, 28 middle-aged professors ( 24 men, 4 women), who averaged 522 years of age (range $=45-59$ years) and 21 years of education, and 22 senior professors ( 19 men, 3 women), who averaged 647 years of age (range $=60-71$ years) and 21 years of education Professors were culled from many disciphnes, including anthropology, biology, English, geology, history, music, physics, psychology, and sociology Professors were recruited by publicizing the study in The Berkeleyan, a newsletter for faculty and staff, by mailing requests to individual faculty, and by telephoning to request volunteers directly Each subject was pard $\$ 15$ for participating in the experiment

For companson purposes, we present data from standard groups of young and old subjects The young subjects consisted of 12 to 40 undergraduate students, depending on the test measure The entire sample of 40 young subjects averaged 198 years of age (range $=18-23$ years) and 14 years of education The standard group of old subjects consisted of 17 individuals with a mean age of 665 years (range $=60-71$ years) and an 
average of 16 years of education We use these groups of subjects as benchmarks for companing the present findings from professors with findings from standard subject samples used in typical studies of cognitive aging (e g , college students vs education-matched older individuals) However, it is inappropnate to compare these subjects directly ( $\mathrm{e}$, statistically) with the professors in terms of the age factor alone In particular, these two control groups differ from the professors in years of education Thus, the central focus of the present study is to delineate the age effects among the professors

\section{General Procedure}

The professors were administered a 90 -min test battery These tests focused on aspects of learnung and memory, as this domain of cognitive function is generally the one most affected by aging (Cralk \& Jennings, 1992, Kausler, 1991, Light \& Burke, 1988) We also included tests of reaction tume, because they too provide sensitive measures of cognitive aging (Botwinıck, 1984, Hicks \& Birren, 1970, Salthouse, 1991) Specific methods and results for each measure are described in the following sections

\section{Reaction Tume}

Response slowing is endemic among normal elderly individuals Indeed, some researchers have viewed response slowing as the primary contributor to many, if not all, age-related declines in cognitive function (Cerella, 1985, Myerson, Ferraro, Hale, \& Lima, 1992) It has been suggested that slowing provides an index of biological aging, perhaps reflecting general neuronal efficacy (Welford, 1958) Previous studies have shown that response slowing in the elderly has a central or cognitive component as opposed to a purely motor locus For example, the difference in reaction time between young and old subjects increases with stumulus complexity or task difficulty (Jordan \& Rabbitt, 1977) Also, age differences appear to reflect a general slowng factor, as indicated by the fact that increases in reaction tume exhibited by elderly individuals as task difficulty increases are proportional to increases exhibited by young individuals (Bnnley, 1965, Cerella, 1985, Myerson et al , 1992)

In the present study, reaction time was assessed by keypress responses to visual stumuli presented with a Macintosh computer Key-press responses were obtained using a response box consisting of a center key and four additional keys (one above, one below, one to the left of, and one to the nght of the center key) In the simple reaction time task, subjects were instructed to depress the center key as soon as a stimulus appeared on the screen The stumulus was etther the word "go" (word condition) or a symbol representing a traffic light (symbol condition) To reduce anticipatory responses, we vaned the duration between a warning cue and the target stimulus between 1,500 and 4,000 ms In the two-choice task, the word ("left" or "right") or symbol (arrow pounting left or nght) indicated whether the key-press response should be to the left or nght key In the four-choice task, the word or arrow indicated whether the key-press response should be up, down, left, or nght Each condition included a total of 32 trials

Figure 1 shows reaction tumes for the simple, two-choice,
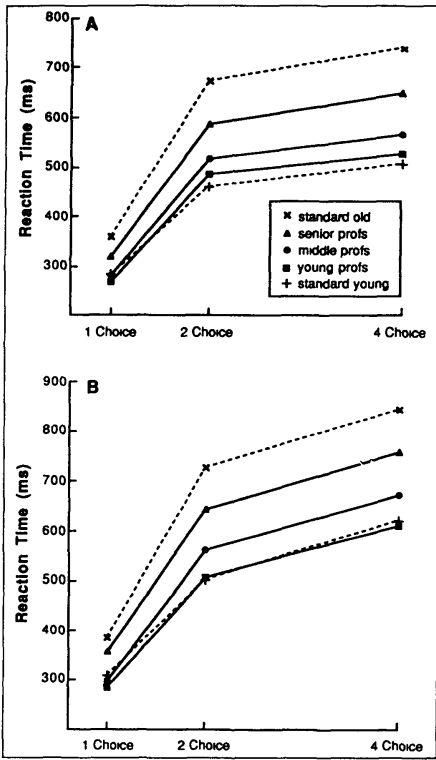

Fig 1 Reaction time on one-choice (simple), two-choice, and four-choice tests with arrow stimuli (a) and word stimul (b) Dashed lines represent data from standard groups, solid lines represent data from professors

and four-choice tasks Age differences were apparent between the standard young and old groups Specifically, overall slowing was observed $(F[1,59]=99, p<001)$, older subjects exhıbited increased reaction time with increases in choice complexity (Age $\times$ Choice interaction, $F[2,118]=556, p<001$ ), and responses to symbolic ( $\mathrm{e}$, arrow) stimuli were faster than responses to word stımuli $(F[1,59]=193, p<001)$ Simular age effects were observed among the three groups of professors a main effect of age $(F[2,68]=124, p<01)$, an Age $\times$ Choice interaction $(F[4,136]=24, p<05)$, and a main effect of stumulus type $(F[1,68]=113, p<01)$ Thus, older professors exhibited typical patterns of slowing in response to verbal and symbolic stumul 


\section{A P Shimamura et al.}

We performed a correlational analysis between reaction tume and age of professor Only professors were analyzed using this method because the ages of the professors were distnbuted evenly across the age range There was a significant correlation between reaction tume and age $(r=53, p<05)$ A linear regression analysis revealed a least square regression slope of $39 \mathrm{~ms} / \mathrm{year}$, which is the estimated rate of response slowing among professors aged 30 to 71 years Thus, the pattern of age-related deficits in professors was similar to that observed in standard groups of young and old individuals

\section{Parred-Associate Learning}

Remembenng arbitrary associations, such as painng a name to a.face or a phone number to a friend, places heavy demands on memory because of the inherent absence of meaningful links Parred-associate learning paradigms have been useful in assessing this aspect of memory (for review, see Crowder, 1976, Postman \& Underwood, 1973) In such paradigms, subjects are presented stımulus pars (e g, table-dollar) and later asked to remember the second item when cued with the first (e $\mathrm{g}$, table-?) Studies of neurological patients have demonstrated that patients with damage to the medial temporal region (e $\mathrm{g}$, hippocampus) exhibit severe impairment in pairedassociate learning tests and in other tests of new learning capacity (Shimamura, 1989, Squire \& Shimamura, 1986) Such findings suggest the role of the medial temporal region may be related to establıshing new associative memones (Rudy \& Sutherland, 1992, Squire, 1992) These findings are relevant to aging research because neuropathology-such as the presence of senile plaques-occurs prominently in the medial temporal region in aged brains Also, atypical forms of aging, such as Alzheimer's disease, can disproportionately affect the medial temporal region and thus the learning of new associations (Meencke, Ferszt, Gertz, \& Cervos-Navarro, 1983)

In the tests of pared-associate learning, face-face pars and name-name pairs were constructed For the face-face test, subjects were presented 6 pairs of faces (4-s exposure duration), with each parr consisting of a line drawing of a female face and a male face Following presentation of the pars, each of the female faces was shown again, and subjects were asked to select from a display of all 6 male faces the one that was associated with each female face For the name-name test, subjects were presented 10 name-name pairs, each consisting of one male and one female name (e g, "Edward \& Nancy") Following presentation of the name pairs, each of the male names was shown agan, and subjects were asked to select from a display of all 10 female names the one that was associated with each male name We developed these tests to allow a close comparison between verbal and pictoral memory and to provide a format that older subjects would find practucal Subjects were told that each face and name pair should be remembered as a male-and-female "couple " Also, a recall test for the pictoral (face) test was impractical, so we used a recognition test for both pictoral and verbal tests

Learning was assessed across three successive study-test tnals As shown in Figure 2, age-related changes were observed in the performance of the standard young and old groups on
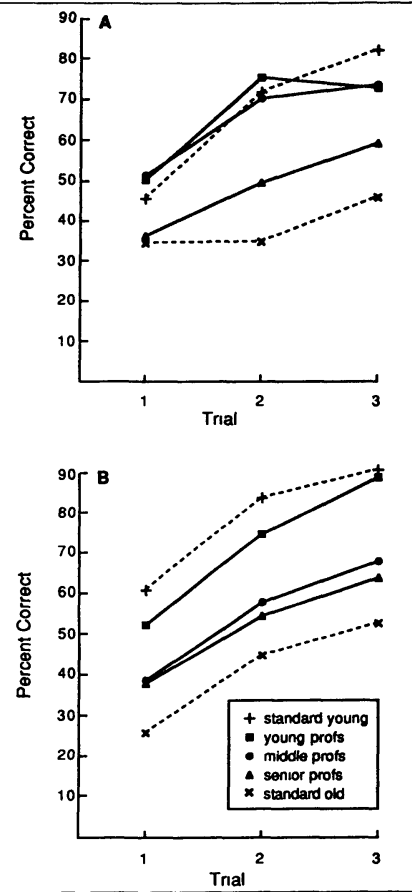

Fig 2 Paired-associate memory across three successive studytest trals with face-face pars (a) and name-name pars (b) Dashed lines represent data from standard groups, sohd lines represent data from professors

tests of parred-associate learning for both face $(F[2,66]=204$, $p<01)$ and name $(F[2,66]=672, p<01)$ pars Age-related memory changes were also observed among the groups of professors for both the face test $(F[2,69]=418, p<05)$ and the name test $(F[2,69]=614, p<01)$ As in the analysis of reaction tume, the pattern of performance by the professors was 
simular to that observed in standard control groups of young and old adults The professors were not immune to the age effects assoctated with the learning of arbitrary information

An interesting pattern of performance emerged in the analysis of verbal and nonverbal memory For face-face pars, a significant age effect was observed between middle-aged professors and senior professors $(t>132, p<05)$ The young and middle-aged professors performed sumilarly For name-name pars, a significant age effect occurred earher, that is, a sıgnificant effect was observed between the young and middle-aged professors ( $t s>119, p<05$ ), but there was no difference between the middle-aged and senior professors These findings suggest differences in the tume course of age-related changes in memory for verbal and nonverbal matenal and suggest the need for further analyses using middle-aged subjects

\section{Working Memory}

Working memory refers to a short-term memory process that is involved with on-line monitoning or control of information (Baddeley, 1986) Performance on tasks involving workıng memory is disrupted by frontal lobe lesions (Goldman-Rakıc, 1987 , Petndes \& Mulner, 1982, Shumamura, 1994) This finding is particularly relevant to studies of aging because neuronal atrophy due to the normal aging process occurs in the frontal lobes more than any other cortical regions (Haug et al , 1983, Ivy, MacLeod, Petit, \& Markus, 1992)

We administered the self-ordered pointıng task, a workıng memory test that is sensituve to frontal lobe pathology in humans (Petndes \& Milner, 1982) In this test, subjects are shown repeated presentations of a computer-generated array of visual patterns (see $\mathrm{F}_{1 \mathrm{~g}}$ 3a) On each of 16 presentations, the patterns were arranged randomly in the array, and subjects were instructed to point to a pattern, with the restriction that they should point to a different pattern on each tral This task required subjects to monitor responses to stumuli across a block of 16 trials We increased the demand on working memory by having subjects perform the task agan in a second block of trials using the same stımulus patterns In this way, we required subjects to monitor and remember responses made within a block and between blocks of trals

A study of age effects on the self-ordered pointıng task (Sh1mamura \& Junca, 1994) showed that standard groups of older adults between the ages of 60 and 70 perform as well as young adults on the first block of trals but fall to maintain a low error rate on the second block of trials (see Fig 3b) One explanation for this finding is that older adults have problems discriminating responses made on the first block of trals from those made during the second block This finding is in accord with recent studies in which aging appears to affect the ability to inhibit or disregard urrelevant or interfening information (Hasher, Stoltzfus, Zacks, \& Rypma, 1991) Such disruptions can be viewed as a consequence of increased proactive interference-that is, a decrement in memory performance as a result of interference from pnor expenences Problems associated with increased proactive interference or problems in inhibiting extraneous information are often observed in patients with frontal lobe le-

\section{A}
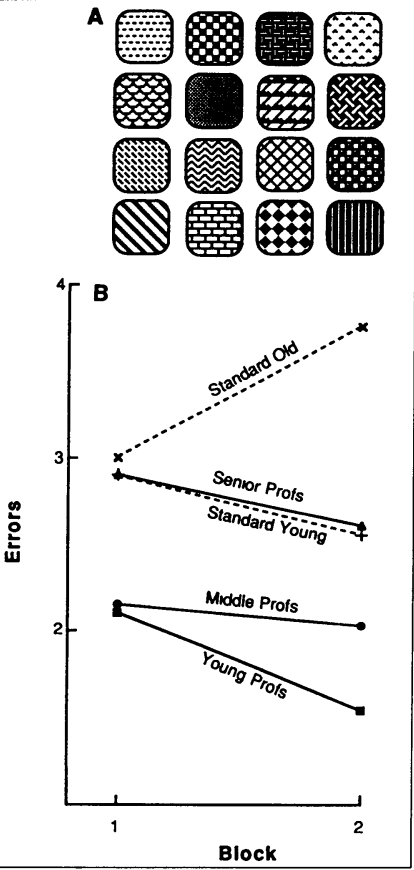

Fig 3 Stımulus array (a) for the self-ordered pointing task and mean error scores (b) on that task for professors and standard groups (data from Shimamura \& Junca, 1994)

sıons (Shımamura, Junca, Mangels, Gershberg, \& Knight, 1995) and in older adults (Hartman \& Hasher, 1991)

The professors performed well on the self-ordered pointung task Age differences were observed among the three groups of professors, $F(2,66)=329, p<05$ Yet there was an important quahtative difference between the pattern of the age effects in the professors and in the standard old group None of the groups of professors exhbited an increase in errors across test 
blocks It may be that professors were better able to devise and use efficient strategies to prevent or reduce the influence of proactive interference Nonetheless, the finding of an age effect among the groups of professors suggests that some abilities tapped by this test are age-dependent

\section{Prose Recall}

A prominent feature of intellectual activity is the acquisition and organization of conceptual knowledge Tests of prose recall assess subjects' ability to incorporate and retain new facts within an existıng knowledge base Significant age decrements are typically observed on tests of prose recall, although decrements can be mitıgated by high verbal ablity (Hartley, 1989, Meyer \& Rice, 1981) In the present study, subjects heard three prose passages-a standard prose passage used in clinical assessment of memory, a prose passage involving scientific information, and a prose passage involving histoncal-anthropological information

Each prose passage was tape-recorded and presented auditorily to the subjects One passage came from the Wechsler Memory Scale-Revised (WMS-R, Wechsler, 1987) and consisted of a fictional story about a woman, Anna Thompson, who was robbed In this standard test, the text is divided into 25 conceptual phrases or segments, and performance is scored as the percentage of segments recalled Two other passages were obtained and segmented One involved scientific information about the elements that make up the earth's atmosphere The other passage involved anthropological-histoncal information about the tribal cultures in the Mississippian penod Recall performance for these two passages was based on memory for 25 conceptual phrases per passage and scored in the same manner as the text used in the WMS-R

Prose recall was assessed immediately after presentation of the passage Age-related changes were observed in the comparIsons between the standard young and old groups, $F(2,67)=$ $166, p<01$ In contrast, professors of all ages performed well on tests of prose recall (see Fig 4) Indeed, on the three different prose passages, senior professors recalled as many detals as young professors, $F(2,69)=16, p>2$

\section{DISCUSSION}

This investigation of cognitive and memory performance in professors highlighted several factors associated with aging On two tests - tests of reaction time and pared-associate learning-age-related decrements observed in professors were sumlar to those observed in standard studies of aging Thus, professors were not completely immune to age-related cognitive changes In partucular, slowing appeared to be a strong predictor of age and perhaps the best predictor of biological factors associated with the aging process Findings of age-related deficits in parred-associate learning suggest that intelligence and mental activity during adulthood cannot prevent problems in memory for arbitrary associations, such as associating names to faces or phone numbers to colleagues Arbitrary associations may be particulariy affected because such associations do not significantly draw upon conceptual knowledge or reasoning
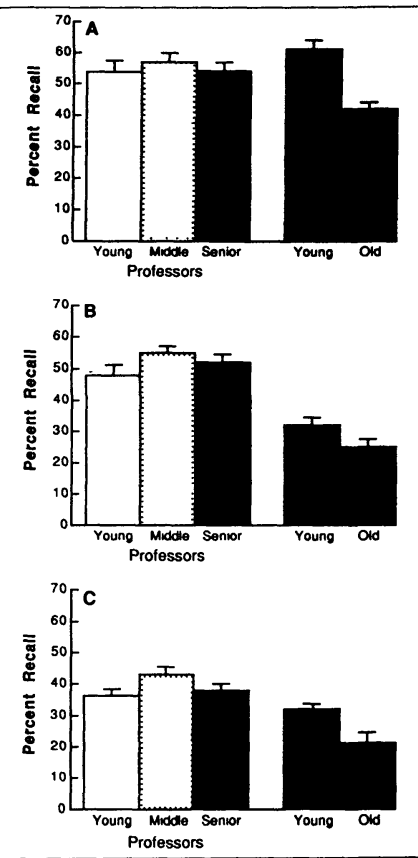

Fig 4 Recall performance for a prose passage used in the Wechsler Memory Scale-Revised (a), a prose passage concerning scientific facts about the earth's atmosphere (b), and a prose passage concerning anthropological-historical information about the Mississippian penod Bars on the left represent data from professors, and bars on the nght represent data from standard groups Error bars refer to standard errors of the mean

In the present study, age effects in two domans of cognitive function appeared to be different from the effects observed in standard studies of aging In the self-ordered pointing test, proactive interference across blocks of trals, which was observed in a previous study of aging (Shimamura \& Junca, 1994), was 


\section{Memory and Cognituve Abulity in Professors}

not apparent in the performance of professors Although overall errors in this task did increase with age among the professors, none of the age groups exhibited the disproportionate increase in errors from the first to the second block of trials Thus, an aspect of this test of working memory was immune to age decrements Finally, prose recall performance was equivalent for senior, middle-aged, and young professors Interestingly, these two memory measures-proactuve interference and prose recall-are typically very sensitive measures of age-related decline

The findings from this spectal population offer some unique insights into the spectrum of aging patterns observed in adulthood In particular, these findings provide information concerning exceptional or boundary conditions of performance Agerelated effects have been studied in other special populations, including pulots, skılled technicians, and business executives (for review, see Salthouse, 1991) Indeed, Sward (1945) assessed young (age 25-35 years) and senır (age 60-79 years) professors on a variety of mental abilitıes, including tests of anthmetic, verbal ability, symbol substitution, and problem solving He observed age decrements on six of the eight test measures The most prominent declines occurred on the two tests with time limitations, suggesting that the deficits may be related to cognitive slowing In addition, many of these tests involved arbitrary association of novel symbols to digits or words ( $\mathrm{g}$, symbol-digit substitution task) In the present study, professors' age-related deficits on tests of reaction time and arbitrary paired-associate learning are consistent with Sward's findings Sward did not find aging effects on two tests-identifying synonyms and antonyms and identifying word meanings

There are several prominent dufferences between the present study and the one by Sward (1945) First, we assessed only actively employed professors, whereas the previous study included emeriti professors Second, we assessed primarily memory abilities rather than intellectual abilities Third, we did not subject the professors to arduous, mentally taxing problems, whereas in the previous study, 11 older and 4 younger professors complained of being tired durng a session Nevertheless, Sward's conclusions closely match ours Specifically, Sward viewed the prumary age effect as one of cognitive slowing and was more impressed by individual differences than by the effects of aging among professors

In the present study, there is an interesting commonality between the test measures that showed no or little age effect Specifically, the mitugation of proactive interference and prose recall require planning, organization, and the manipulation of information in memory. They also draw considerably upon contextual information-information embedded within a spatiotemporal framework or within a knowledge-based framework These two factors are related because access to information whthin a contextual framework requires efficient planning, organization, and retneval strategies Perhaps professors are facle in their use of such strategies to access knowledge as a result of daly actuvitues that require the integration of new knowledge into existung knowledge representations Their facility with these strategies may compensate for decrements in the mechanics of cogmituve function, such as decrements caused by cognituve slowng
In standard groups of elderly individuals, tests that tap higher order abilities, such as planning, organization, and problem solving, are generally the most affected Thus, the preservation of performance on these tests in professors stands in marked contrast to typical findings from studies of aging Neuropsychological investigations have demonstrated that the deployment of higher order strategies is particularly affected by frontal lobe lesıons (for review, see Moscovitch, 1992, Shımamura, 1994, Stuss, Eskes, \& Foster, 1994) Generally, patıents with damage to the dorsolateral prefrontal cortex exhibit impairment on tests of problem solving, planning, and working memory (Baddeley, 1986, Milner, Petndes, \& Smith, 1985, Stuss et al , 1994) Moreover, they are more susceptible to proactive interference (Shimamura et al , 1995), exhibit impairment on tests of free recall (Gershberg \& Shumamura, in press, Jetter, Poser, Freeman, \& Markowitsch, 1986), and do not appear to organize memory efficiently (Eslınger \& Grattan, 1994, Gershberg \& Shimamura, in press) As mentioned, these neuropsychological findings are important for the study of normal aging because neuronal atrophy due to the normal aging process occurs most prominently in the frontal lobes (Haug et al , 1983)

This investigation suggests two possibilities in terms of the biological foundation underlying aging and cognitive function One possibility is that mental activity reduces the changes that typically occur as a result of aging That is, mental activity may protect cognitive functions from typical age-related changes of course, mental activity cannot be the only factor, genetic factors and other early influences must also contribute significantly to the status of mental and neural function in later life Another possibility is that age-related changes occur to the same extent in all individuals, including professors, and that professors' preserved performance on behavioral measures is the result of an enhanced ability to compensate for decrements For example, efficient use of memory strategies developed during adulthood may compensate for biological aging effects, such as generalized slowing The present findings suggest a compensatory role of mental activity because clear age-related declines were observed in the basic mechanics of cognitive function (e $\mathrm{g}$, reaction time) However, more direct analyses, perhaps involving noninvasive neuroimaging techniques (e g, magnetıc resonance imaging), may provide important clues to the ways in which individuals adapt successfully to the aging process

Acknowledgments-This research was supported by a grant from the National Institute on Aging (AG09055) to A P Shumamura and a National Science Foundation Graduate Research Fellowshup to J A Mangels We thank Stephane Erber, Kathenne Stone, and the staff at the Institute for Personality and Social Research (University of Califorma, Berkeley) for research assistance

\section{REFERENCES}

Albert, M S , Duffy, F H , \& Naeser, M (1987) Nonlinear changes in cognition with age and their neuropsychologeal correlates Canadian Journal of Psy. chology, 41, 141-157

Baddeley, A (1986) Workang memory Oxford, England Oxford Unversity Press

Battes, P B \& Baltes, M M (Eds) (1990) Successful aging Perspectrves from the behavioral sciences Cambndge England Cambindge Unversity Press Botwnick, J (1934) Aging and behavior (3rd ed ) New York Springer 


\section{A.P Shimamura et al}

Bruniey, J F (1965) Cognituve sets, speed and accuracy of performance in the elderly In A T Welford \& I E Birren (Eds), Behavior, aging and the nervous system (pp 114-149) Sprngfield, IL Springer

Cerella, J (1985) Information processing rates in the elderty Psychological Bulletin $96,67-83$

Crak, F I M , \& Jenaings, J M (1992) Human memory In F I M Crat \& T A Salthouse (Eds). The handbook of aging and cognition (pp 51-110) Hillsdiale, NJ Eribaum

Crowder, R G (1976) Pruncuples of learning and memory Hillsdale, NJ Erbeum

Eshnger, P J , Grattan, L M (1994) Attered senal position learnung after frontal lobe iesion Newropsychologia 32 729-739

Gershberg. F B, S Shimamura, A P (in press) The role of the frontal lobes in the use of organizational strategres in free rocall Neuropsychologia

Goldman-Rakac, P S (1987) Curcurtry of pnimate prefrontal cortex and regulation of behavior by representational memory In F Plum (Ed), Handbook of physiology The nervous system (Vol 5, pp 373-417) Bethesda. MD American Physiologeal Socrety

Hartky, J T (1989) Memory for prose Perspectuves on the reader In L W Poon, D C Rubin, B A Walson (Eds), Everyday cognition in adulthood and late lufe (pp 135-156) Cambridge. England Cambndge University Press

Hartman M , Hasber, L (1991) Agang and suppression Memory for previ* ously relevant information Psychology of Aging, 6, 587-594

Hasher, L, Stoltzfus, E R, Zacks, R T , \& Rypma B (1991) Age and ınhıbiton Journal of Experimental Psychology Learning Memory, and Cognithon, 17, 163-169

Haug. H , Barmwater, U , Eggers R , Fischer, D , Kuhl, S , \& Sass N L (1983) Anatomucal changes in aging brarn Morphometnc analysis of the human prosencephalon In J Cervos-Navarro \& H I Sarkander (Eds), Brain aging Neuropathology and neuropharmacology (pp 1-12) New York Raven Press

Heron, A, \& Chown, S (1967) Age and function Boston Little Brown

Hicks, L H , \& Burren, J E (1970) Aging, brain damage, and psychomotor slowing Psychologucal Bulleten 74, 377-396

Ivy, G O , MacLeod, C M , Pett, T L , \& Markus, E J (1992) A physiological framework for perceptual and cognition changes in aging In F I M Craik \& T A Salthouse (Eds), The handbook of aging and cognition (pp 273-314) Hillsdale NJ Eribaum

Jetter, W , Poser, U . Freeman, R B \& Markowitsch H J (1986) A verbal long term memory deficit in frontal lobe damaged patients Cortex $22 \quad 229-242$

Jordan, T C , \& Rabbitt, P M A (1977) Response tumes to stumulu of increasing complexity as a function of ageing British Journal of Psychology 68189 201

Kausler, D H (1991) Experimental psychology and human aging (2nd ed) New York Springer-Veriag

Lught L L, \& Burke, D M (1988) Language memory and aging New York Cambndge Unuversity Press

Meencke, H J , Ferszt, R , Gertz, H J , \& Cervos-Navarro J (1983) Hippocampal pathology in normal aging and dementua In $\mathrm{J}$ Cervos-Navarro \& $\mathrm{H}$ I Sarkander (Eds), Brain aging Neuropathology and neuropharmacology (pp 13-26) New York Raven Press

Meyer, B J F, Rice, G E (1981) Information recalled from prose by young. muddle, and old adults Expenmental Aging Research 7 253-268

Milner, B , Petndes, M , \& Smith, M L (1985) Frontal lobes and the temporal organization of memory Human Neurobiology 4 137-142
Moscovitch, M (1992) A neuropsycholopeal model of memory and consciousness in L R Squtre \& N Butters (Eds), Newropsychology of memory (2nd od, pp 5-22) New York Gulford Press

Myerson J, Femaro, F R. Hale S, \& Lama, S D (1992) General slowise in semantic primins and word recognmion Psychology and Aging $7257-270$

Pertmutter, M (1978) What is memory aens the aans of Developmental Psychology 14 330-345

Petrides, M, Milner B (1982) Deficits on subject-ondered tasks after frontafand temporal-tobe lesions in man Neuropsychologie 20, 249-262

Postman L. \& Underwood, B J (1973) Cnucal issues in interference theory Memory and Cognition $1,19-40$

Rudy J W \& Sutherland, R J (1992) Configural and elemental associatrons and the memory cohereace problem Journal of Cognitive Neuroscience 4. 208-216

Salthouse, T (1991) Theoretical perspectives on cognutive aging Hillsdale, NJ Erlbaum

Schase K W (1990) The optumization of cognituve functioning in old Pre. dictions based on cohort-sequentral and longtudinal data In P B Baltes a M M Baltes (Eds), Successful aging Perspectives from the behavioral sciences (pp 94-117) Cambridge, England Cambndge University Press

Schase, K W (1994) The course of adult intellectual development Amencan Psychologist 49 304-313

Shimamura, A P (1969) Disorders of memory The cognituve science perspective In F Boller \& J Grafman (Eds), Handbook of neuropsychology (pp 35-73) Amsterdam Elsevier Sciences Publishers

Shimamura, A P (1990) Aging and memory disonders A neuropsycholopeal analysts in M L. Howe, M.J Stones, \& C J Brainerd (Eds), Cognitrue and behavioral performance factors in afypical aging (pp 37-65) New York Springer-Verlag

Shimamura, A P (1994) Frontal lobes and memory In M S Gazzaniga (Ed). The cognulve neurosciences (pp 803-813) Cambndge, MA MIT Press

Shımamura, A P \& Junca, P J (1994) Memory unterference effects and agang Findings from a test of frontal lobe function Neuropsychology 8, 408-412

Shimamura, A P Junca P J Mangels I A Gershberg, F B , Knught, R T (1995) Susceptibility to memory interference effects following frontal boe damage Findings from tests of pared-associate learning Journal of $\mathrm{Cog}^{-}$ nutuve Neuroscience $7 \quad 144-152$

Squire L R (1992) Memory and the hippocampus A synthesis from findines with rats, monkeys, and humans Psychological Review 99 195-231

Squire LR \& Shimamura AP (1986) Charactenzing amnesic patieats for neurobehavioral study Behavioral Neuroscience, 100, 866-8T7

Stuss D T Eskes G A \& Foster J K (1994) Expenmental neuropsychological studies of frontal lobe functions In F Boller I Grafinan (Eds). Handbook of neuropsychology (pp 149-185) Ainsterdam Elsevier

Sward, K (1945) Age and mental abilities in supenor men American Journal of Psychology $58 \quad 443-479$

Wechsler D (1987) Wechsler Memory Scale-Revised San Antomo, TX Hercourt Brace Jovanovich

Welford, A T (1958) Ageing and human skall London Oxford University Press

Zelinsk, E M Gilewski, M J , \& Schare, K W (1993) Individual differences in cross-sectional and 3-year longitudinal memory across the adult life span Psychology and Aging $8 \quad$ 176-186

(RECEIVED 5/10/94, ACCEPTED 10/2/94) 
This document is a scanned copy of a printed document. No warranty is given about the accuracy of the copy. Users should refer to the original published version of the material. 